\title{
ANALYSIS OF NEAR FIELD DISTRIBUTION VARIATION USING AWAS ELECTROMAGNETIC CODE FOR WIMAX
}

\author{
Chhaya Dalela ${ }^{1}$, MVSN Prasad $^{2}$, Rahul Namawat $^{3}$ \\ ${ }^{1}$ Department of Electronics \& Communication Engineering, JSSATE, Noida, \\ India \\ ${ }^{1}$ chhayadalelaejssaten.ac.in \\ ${ }^{2}$ National Physical Laboratory, New Delhi, India, \\ ${ }^{2}$ mvprasad@mail.nplindia.ernet.in \\ ${ }^{3}$ JECRC University, Jaipur, Rajasthan, India \\ ${ }^{3}$ rahulnamawat@gmail. com
}

\begin{abstract}
Rapid Fluctuations and variations of signal strength at higher frequency range in Near Field zone, is a common difficulty to achieve higher data rate. As signal varies continuously, it starts decaying by the interference of the atmospheric obstructions and the electric field intensity gradually decreases with the distance. This effect is observed by AWAS Electromagnetic Code which predicts the rapid variations in electric field intensity irrespective of environment, whereas statistical models do not capture the fundamental physics and variations as per Environment. An Adequate and optimum values of these external parameters is essential for controlled and efficient transmission.
\end{abstract}

\section{KEYWORDS}

WiMAX, Propagation Modelling, Near Field Zone, Electric Field Intensity, Electromagnetic Code

\section{INTRODUCTION}

Worldwide Interoperability for Microwave-Access (WiMAX) has emerged as wireless access technology that is capable of providing fixed and mobile broadband connectivity. Fixed WiMAX is targeted for fixed and nomadic broadband services while mobile WiMAX are designed to provide high mobility services. Operators do drive-tests on a continuous basis, collect signal levels, network quality and performance which are then used to refine empirical propagation models for system-planning and/or existing network optimization. The fast evolution of wireless communications has led to the use of higher frequency bands, smaller cell sizes, and smart antenna systems, making the propagation prediction issues more challenging since wireless communication channels are inherently frequency dispersive, time varying, and space selective. These data rates can be further increased by employing multiple antennas both at the transmitter and receiver.

In India, WiMAX is operating at $2300 \mathrm{MHz}$ frequency band which is tends to provides an access to operate the wireless devices at very higher data rates and ubiquitous access in a large coverage

Dhinaharan Nagamalai et al. (Eds) : ACITY, WiMoN, CSIA, AIAA, DPPR, NECO, InWeS - 2014 pp. 329-336, 2014. (C) CS \& IT-CSCP 2014

DOI : $10.5121 /$ csit.2014.4533 
area $[1,2]$. Propagation Models are developed to estimate various parameters viz field strength, path loss etc. in different environments. Propagation Models are for telecommunication providers to improve their services for better signal coverage and capacity for mobile user satisfaction in the area. Prasad etal. [3] reported that the AWAS Electromagnetic Code did not require any building information and was able to compete with other empirical methods. An attempt has been made by the authors to realize the objective by interpreting available experimental data to get a better understanding of the propagation conditions models for different environments to provide guidelines for cell planning of WiMAX transmissions in the Indian urban zones in general. The experimental data utilized in this study corresponds to $2300 \mathrm{MHz}$ WiMAX radio measurements in different environments, carried out in Western India. AWAS Electromagnetic code, which is based on Sommerfield's approach for ground, is used to compute the near field signal strength of propagation link and significant changes with height of transmitting antenna is identified to radiate efficient signal for WiMAX.

In Section II, the details of AWAS Electromagnetic code and Environmental details are provided. In section III, we have analysed AWAS Electromagnetic code with Existing Prediction Methods. Conclusions are presented in Section IV.

\section{EXPERIMENTAL DETAILS}

\subsection{The AWAS Numerical Electromagnetic Code}

AWAS Numerical Electromagnetic Code [4] is a computer program which evaluates the current distribution of a conductor by analysing the polynomial coefficients. This program is based on a two potential equations which is solved numerically using method of moments with polynomial approximation for the current distribution. The influence of the ground is taken into account using Sommerfield's approach, with numerical integration algorithm developed for this program. It was utilized to compute the path-loss values for different values of dielectric constant and a conductivity of $2 \times 10-4$ over real ground. This commercially available computer program is capable of analyzing wire antennas operating in transmitting and receiving modes, as well as analyzing wire scatterers. Different values of dielectric constant for dense urban, urban, and suburban regions were incorporated into the computation of the A WAS simulation. Reference [5] gave relative dielectric constants for various types of ground and environments. It gave values of 3 to 5 for city industrial areas. Hence, a value of 4 was used in the A WAS simulation. In the AWAS simulation, the computation of the electric field was carried out by taking a vertical dipole located over an imperfect ground plane, whereas in the measurements, a high transmitting- gain antenna was employed.

\subsection{Environmental Details}

The experimental sites AAC, AHT, BTW, KTB, GRJ, JVD, and OLK [6] are situated in the dense urban area of Mumbai, India, except AAC, JVD, and OLK, which are located in an urban area [Fig. 1(a) and (b)]. The clutter environments of these sites are shown in different colors in the legend of Fig. 1(a) and (b). Since AAC [Fig. 1(a)] and OLK [Fig. 1(b)] are surrounded by skyscraper buildings, they represent a typical dense urban environment. AHT [Fig. 1(a)] shows the presence of skyscrapers at north, east, and west sides, while the remaining other areas BTW and GRJ are fully surrounded by dense environment. They are surrounded by industrial environments at eastern side of $0.7 \mathrm{~km}$ and at eastern side after $0.9 \mathrm{~km}$ respectively [6]. The parameters of these base stations are shown in Table I and Table II. 


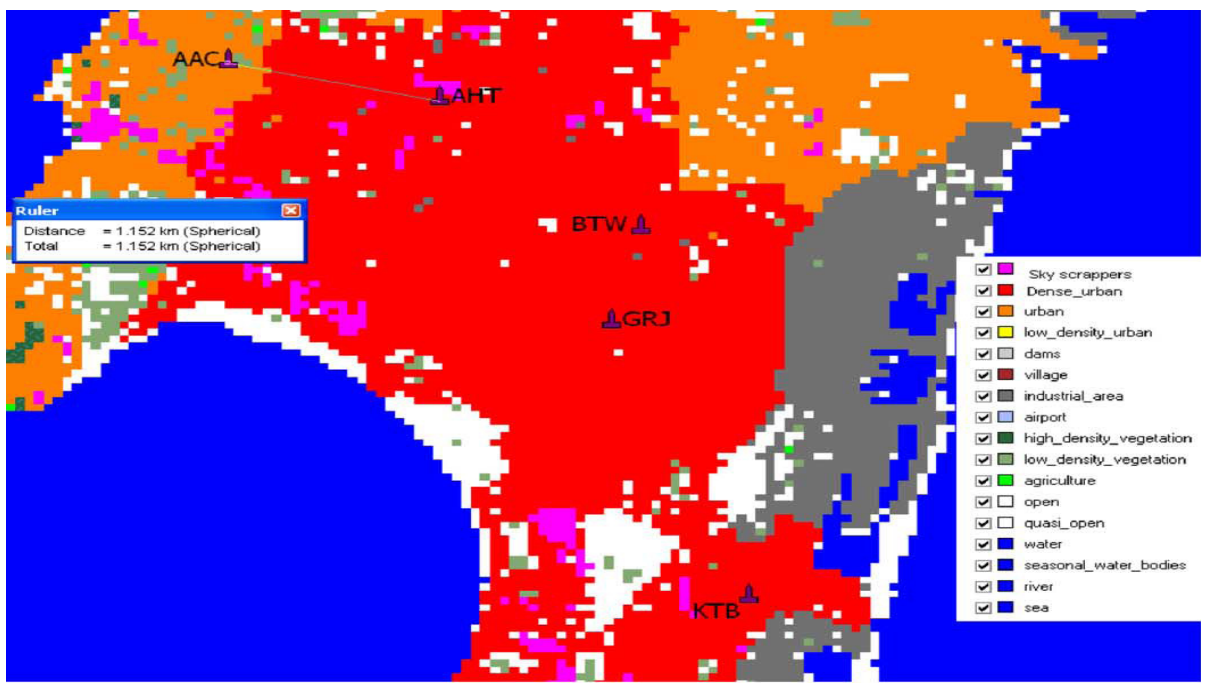

(a)

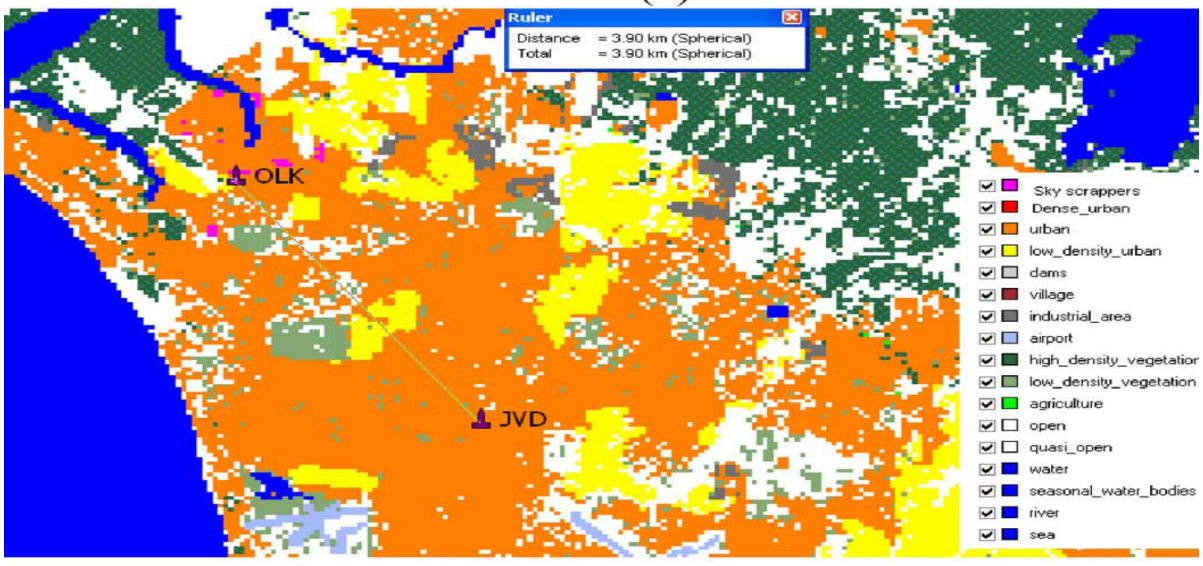

(b)

Fig. 1. Clutter environment for experimental sites (a) AAC, AHT, KTB, BTW, and GRJ and (b) OLK and JVD.

TABLE I

Base Station details

\begin{tabular}{|c|c|c|c|}
\hline $\begin{array}{c}\text { Sr. } \\
\text { No. }\end{array}$ & $\begin{array}{c}\text { Name of Base } \\
\text { Stations }\end{array}$ & $\begin{array}{c}\text { Height of } \\
\text { Transmitti } \\
\text { ng } \\
\text { Antenna }\end{array}$ & $\begin{array}{c}\text { Near Field } \\
\text { Distance } \\
\text { (in Km) }\end{array}$ \\
\hline 1. & Ajay-Amar (AAC) & $37 \mathrm{~m}$ & 1.70 \\
\hline 2. & Arihant (AHT) & $32 \mathrm{~m}$ & 1.47 \\
\hline 3. & $\begin{array}{c}\text { Bootwala Bldg } \\
\text { (BTW) }\end{array}$ & $46 \mathrm{~m}$ & 2.11 \\
\hline 4. & $\begin{array}{c}\text { Khethan Bhabhan } \\
\text { (KTB) }\end{array}$ & $31 \mathrm{~m}$ & 1.42 \\
\hline 5. & Giriraj (GRJ) & $28 \mathrm{~m}$ & 1.28 \\
\hline 6. & $\begin{array}{c}\text { Jeevan Dhara } \\
\text { (JVD) }\end{array}$ & $27 \mathrm{~m}$ & 1.24 \\
\hline 7. & Obelisk (OLK) & $30 \mathrm{~m}$ & 1.38 \\
\hline
\end{tabular}


TABLE III

Other details of experimental site

\begin{tabular}{|c|c|c|}
\hline Sr. & \multicolumn{2}{|l|}{ Other Details } \\
\hline 1. & $\begin{array}{l}\text { Height of Receiving } \\
\text { Antenna }\end{array}$ & $1.5 \mathrm{~m}$ \\
\hline 2. & Transmitted Power & $43.8 \mathrm{dBm}$ \\
\hline 3. & $\begin{array}{lll}\text { Average } & \text { Height } & \text { of } \\
\text { Building } & & \\
\end{array}$ & $25 \mathrm{~m}$ \\
\hline 4. & Average Street Width & $15 \mathrm{~m}$ \\
\hline 5. & $\begin{array}{l}\text { Average Separation } \\
\text { Between Buildings }\end{array}$ & $30 \mathrm{~m}$ \\
\hline
\end{tabular}

\subsection{Electric Field Distribution Analysis}

Electric Field is an important factor in analysing the path loss and its effects in WiMAX. AWAS Electromagnetic code is implemented to calculate the electric field density $(\mathrm{V} / \mathrm{m})$ and then further sustained path loss of the Base Stations in this environment can be calculated. The Near Field distribution of base stations is determined for near field distance (in $\mathrm{Km}$ ) (Table I) for various base stations and are substituted in AWAS Electromagnetic Code in order to estimate the Electric Field Distribution.

Near Field distance is calculated by :

$$
\mathrm{D}=4 * \mathrm{~h}_{\mathrm{t}} * \mathrm{~h}_{\mathrm{r}} / \lambda
$$

where $\mathrm{D}$ is the near field distance and $\mathrm{h}_{\mathrm{t}}, \mathrm{h}_{\mathrm{r}}$ is the height of transmitting and receiving antennas respectively. Fig. 1(a) and 1(b) shows the rapid fluctuations in near field at distance of $100 \mathrm{~m}$ to $200 \mathrm{~m}$ and at $200 \mathrm{~m}$ to $400 \mathrm{~m}$ of GRJ Base Station. A Base Station like GRJ base station is assumed, so the environmental parameters of both the base stations are considered same and treated as a fully dense environment, whose height is considered as 20 meters. Fig 2(a) and 2(b) are near field variations of this base station. By Comparing Fig 1(a), 1(b) and 2(a), 2(b), it was observed that the Field intensity in the Figure 2(a) and 2(b) has less variations as consider to GRJ Base Station.

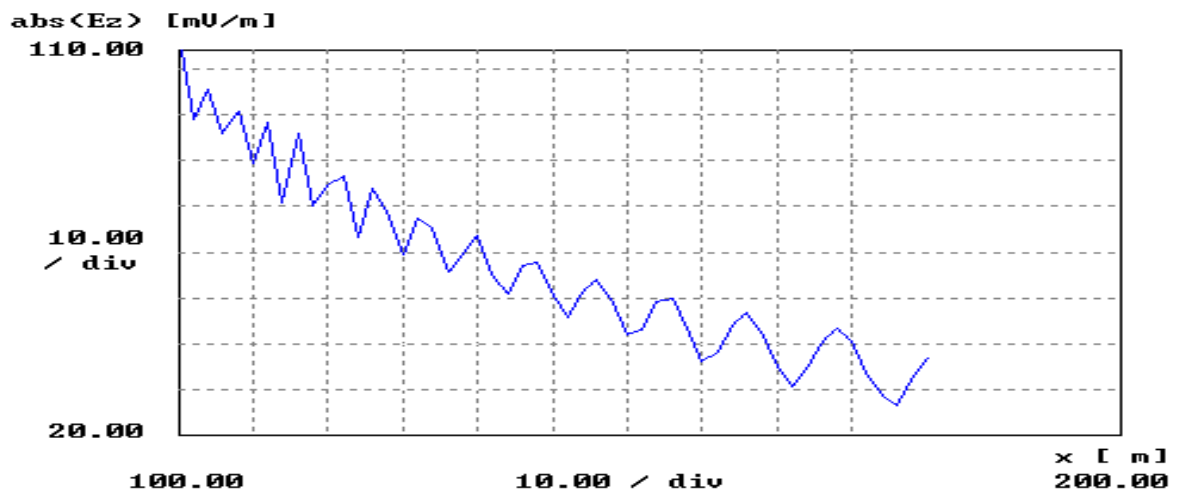

Fig 1(a) : Near Field Distribution of GRJ Base Station from 100m to 200m 


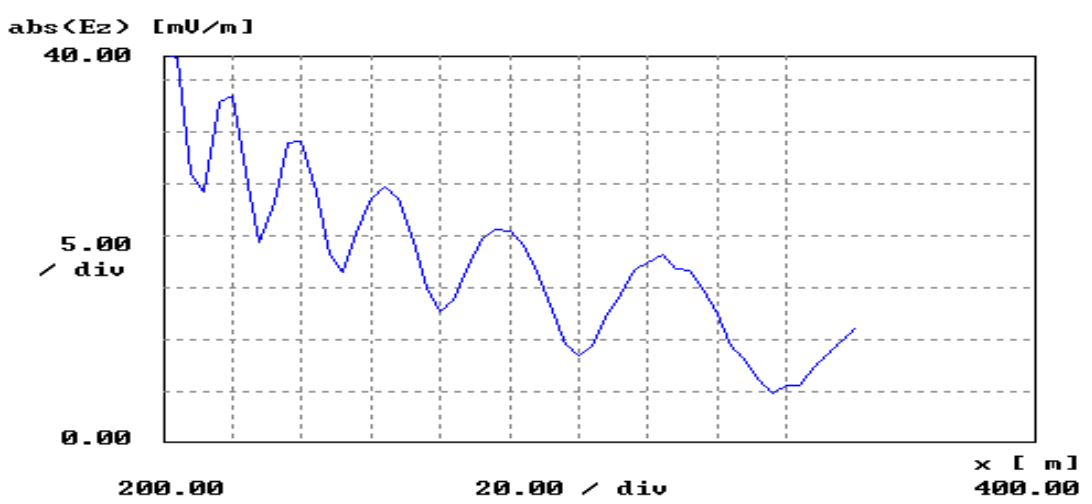

Fig 1(b) : Near Field Variation of GRJ Base Station from 200m to 400m

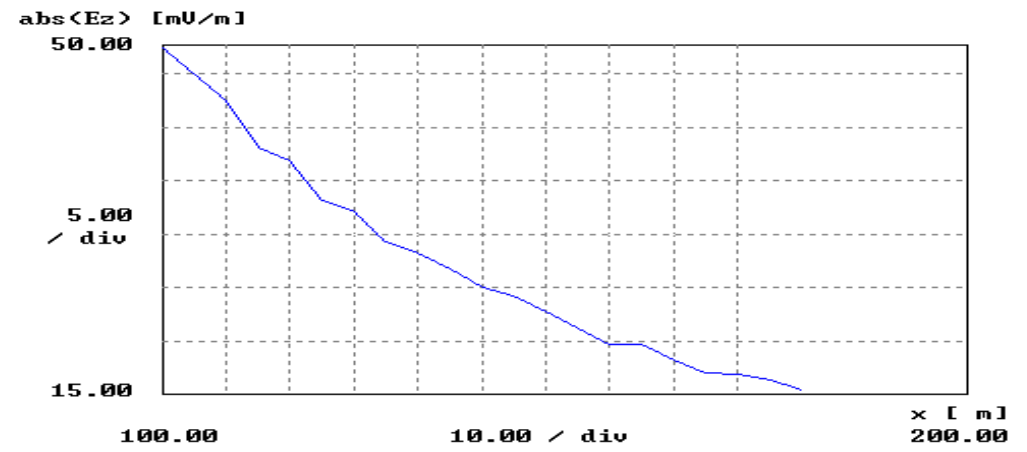

Fig 2(a) : Near Field Distribution of Base Station Antenna of height 20 meters from $100 \mathrm{~m}$ to $200 \mathrm{~m}$

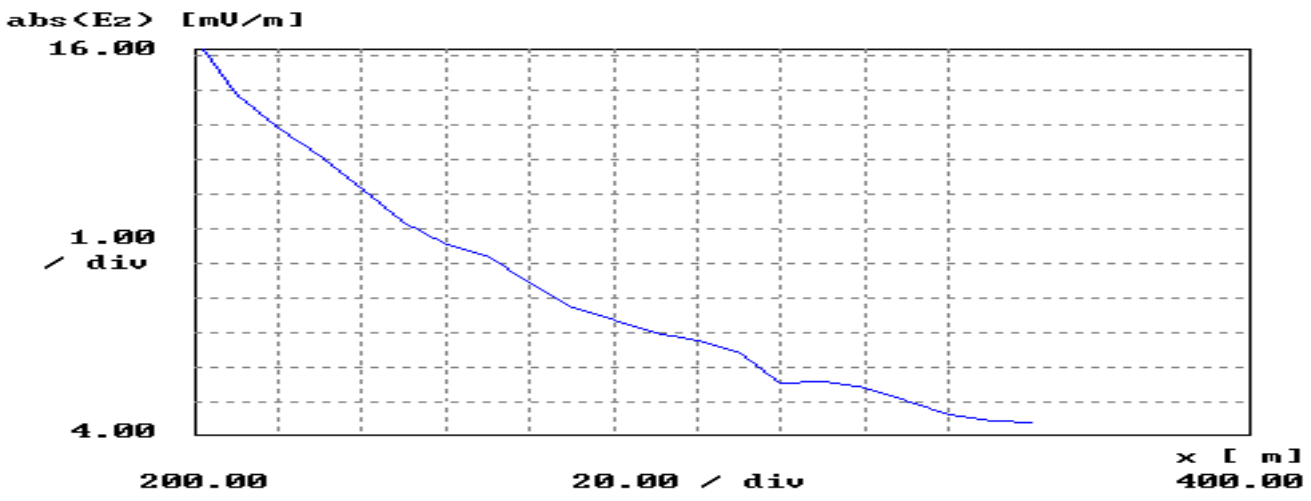

Fig 2(b) : Near Field Distribution of Base Station Antenna of height 20 meters from $200 \mathrm{~m}$ to $400 \mathrm{~m}$ 


\subsection{Analysis of Variations in Electric Field}

As observed from figure 1(a) and 1(b), there is a rapid variations in Electric Field Distribution and can be represented by $\Delta$ which is defined as :

$$
\Delta=\left(E_{\max -} E_{\min }\right) / d
$$

where $d$ is the distance in a single division. Table III shows the variation in electric field which is numerically decreasing with the distance.

TABLE IIIII

RAPID VARIATION IN THE NEAR FIELD OF GRJ BASE STATION AT 2300 MHZ OPERATING FRQUENCY

\begin{tabular}{|c|c|c|c|}
\hline $\begin{array}{c}\text { Sr. } \\
\text { No. }\end{array}$ & $\begin{array}{c}\text { Near Field distance } \\
\text { (meters) }\end{array}$ & \multicolumn{2}{|c|}{$\begin{array}{c}\text { Electric field } \\
\text { Variations }(\mathrm{mV} / \mathrm{m})\end{array}$} \\
\cline { 3 - 4 } & & $\mathrm{H}_{\mathrm{t}}=28 \mathrm{~m}$ & $\mathrm{H}_{\mathrm{t}}=20 \mathrm{~m}$ \\
\hline 1. & $100-110$ & 2 & 0.8 \\
\hline 2. & $120-130$ & 1.5 & 0.6 \\
\hline 3. & $150-160$ & 1.1 & 0.3 \\
\hline 4. & $170-180$ & 1.0 & 0.13 \\
\hline 5. & $200-220$ & 0.8 & 0.1 \\
\hline 6. & $240-260$ & 0.65 & 0.08 \\
\hline 7. & $300-320$ & 0.58 & 0.03 \\
\hline 8. & $400-500$ & 0.14 & 0.015 \\
\hline
\end{tabular}

Basically there are various conventional methods are used to predict the path loss and electric field distribution. But they are unable to predict the variation due to increasing height of the Transmitting Antenna. The reason behind rapid variation in Electric Field in Near Field zone is the atmospheric fluctuation and environmental obstruction. The reduction in variations in Electric field intensity with reduction in height of Transmitting Antenna can be explained as shown in Fig 3. Several repeaters with reduced transmitting antenna height of Transmitting Stations can play a vital role in this situation to remove the rapid fluctuations.

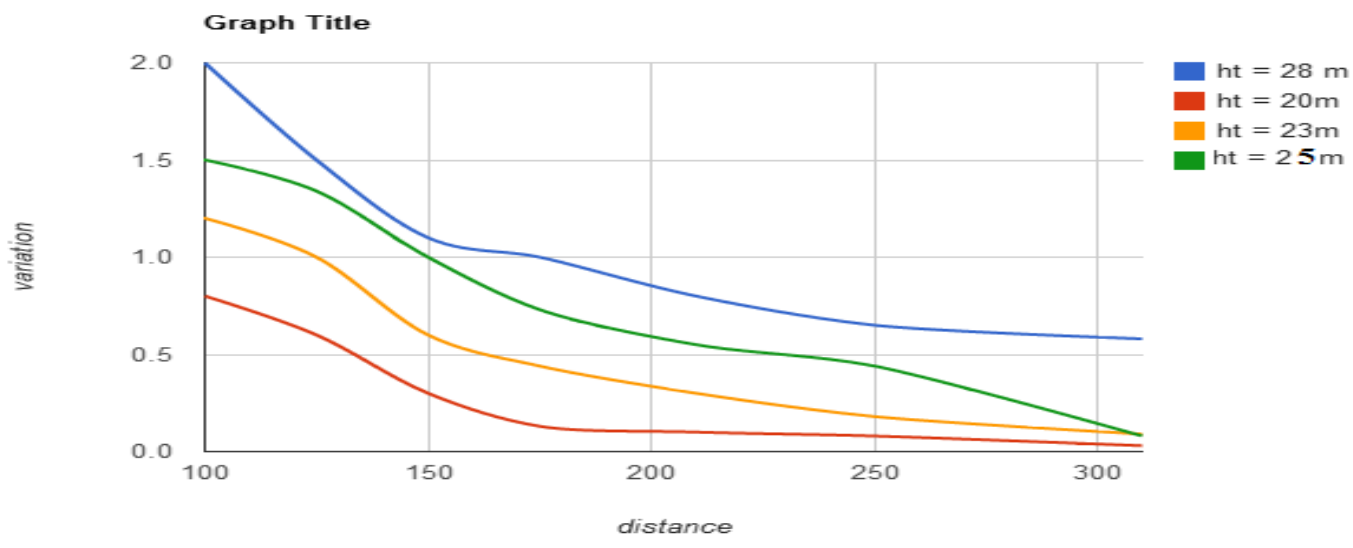

Fig 3 : Variations in Near Field Distribution with change in height of Base Station antenna 


\section{CONCLUSIONS}

The near field distribution for WiMAX at $2300 \mathrm{MHz}$ is analyzed for dense urban region of Western India by AWAS Numerical Electromagnetic Code. The advantage of using AWAS electromagnetic code is that it predicts the fundamental atmospheric variations in the field strength as per the environmental parameters of that region. It has been found that in near field region, signal fluctuations are very high, and as the height of the transmitting antenna increases, near field distance will be larger and the signal remain stable in far field. Hence, it is advisable to keep the antenna closed to the ground and employee more repeater stations. Thus, the reduction in transmitting antenna height will ultimately reduces variation in near field distribution and is achieved to produced efficient radiated signal. Also AWAS numerical Electromagnetic Code predicts all the variations of path loss irrespective of environment whether it is urban, suburban or rural whereas statistical models do not capture the fundamental physics and it has separate models for urban, suburban or rural environment.

\section{REFERENCES}

[1] "IEEE Standards for local and metropolitan area network - Part 16 : Air Interface For fixed broadband wireless access systems”,2011.

[2] CEPT ECC Report 172, "Broadband Wireless Systems usage in 2300-2400MHz”, p. 11, March 2012.

[3] M.V.S.N. Prasad, Saurabh Gupta, M.M. Gupta "Comparison of $1.8 \mathrm{GHz}$ Cellular Outdoor measurement with AWAS Electromagnetic Code and conventional Models over urban and suburban regions of Nothern India”Antenna and Propagation Magazine, IEEE, 53 (2011) 76-85

[4] "Antenna and Wired Scatters"

[5] Soil Dielectric Properties (Dielectric Materials and Applications)," NEC list and Web site: http://pe2bz.philpem. me.uklComm/-\%20AntennalInfo-905-Misc/soildiel.htm; also from Arthur R. von Hippel (ed.), Dielectric Materials and Applications, Cambridge, MA, MIT Press, 1954.

[6] Chhaya Dalela, M.V.S.N Prasad, P.K. Dalela and Rajeev Saraf "Analysis of WiMAX Radio Measurements and Comparison With Some Models Over Dense Urban Western India at $2.3 \mathrm{GHz}$ " IEEE Antenna and Wireless Propagation, 10 (2011)

\section{AUTHORS}

Chhaya Dalela received the B.Tech. degree in Electronics Engg. from H.B.T.I.,Kanpur, M.Tech. in Digital Communication from .P.T.U.,Lucknow and completed her Ph.D. In channel characterisation and modelling. resently, she is working with JSS Academy of Technical Education, Noida, as Associatet Professor in Electronics Engineering Department. Her areas of research interest are channel measurements and modeling for broadband communications, Cognitive Radio, Telecommunication network planning etc. He has published more than 30 research papers in national and international journals and conference proceedings.

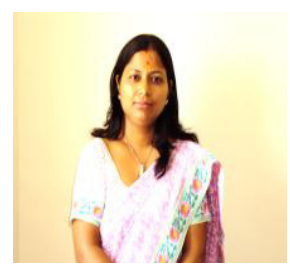


Dr M V S N Prasad is presently working as a scientist in National Physical Laboratory. His research areas are radio channel measurements and modeling for mobile and fixed communications, mobile commnications in railway tunnels, microwave propagation, radiowave propagation related to broadcasting etc. He has developed active links with various user organizations in the area of telecommunications like VSNL, Railways,Dept. of of Telecommunications, three wings of defense and rendered consultancy services in these areas and established collaborations with many universities. He received the URSI young scientist award in

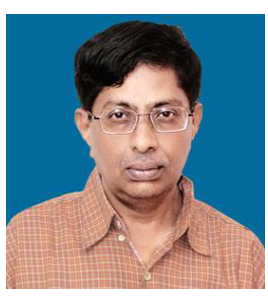
1990, Best paper award from National Space Science Symposium in 1990, Best paper award from Broadcast engineering society( India) in 1998 and 2001. Elected as a member of American Geophysical union under the Lloyd V.Berkner fund. He participated in telecommunication and radio wave propagation workshops at the International centre for theoretical physics, Trieste, Italy. He has published several papers in national and international journals and acted as a reviewer for many journals in this field.

Rahul Namawat received a B.Tech. Degree in Electronics \& Communication Engg. From JECRC UDML College of Engg, R.T.U, Kota. He's currently pursuing in Masters of Technology in Digital Communications from JECRC University, Jaipur.

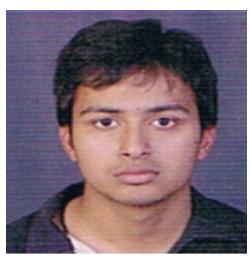

